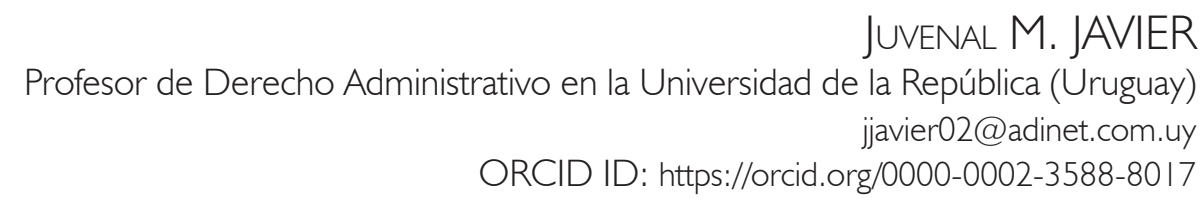

Recibido: 28/05/2021 - Aceptado 30/07/2021

Para citar este artículo / To reference this article / Para citar este artigo Javier, Juvenal M. (202I). El Sistema Nacional de Inteligencia de Estado en Uruguay. Ley 19.696 con las modificaciones introducidas por la Ley de Urgente Consideración 19.889. Revista de Derecho, 20(40), 43-70. https://doi.org// 0.47274/DERUM/40.3

\title{
El Sistema Nacional de Inteligencia de Estado en Uruguay. Ley 19.696 con las modificaciones introducidas por la Ley de Urgente Consideración 19.889
}

Resumen: El trabajo aborda el estudio de la ley 19.696 y su modificativa 19.889, ley de urgente consideración, que regulan el Sistema de Inteligencia de Estado, bajo un estricto contralor y asignándole importantes cometidos a su órgano de mayor importancia, la Secretaría de Inteligencia Estratégica.

Palabras clave: Inteligencia. Inteligencia Estratégica. Inteligencia de Estado. Sistema Nacional de Inteligencia de Estado. Secretaría de Inteligencia Estratégica de Estado. 
The National State Intelligence System in Uruguay. Law 19.696 with the modifications introduced by the Law of Urgent Consideration 19.889

\begin{abstract}
The following article deals with the study of the law number 19.696 and its amendment 19.889, Urgent Consideration Law. Both laws regulate the State System of Intelligence under a strict control and by assigning important tasks to their main organ, the Strategic Intelligence Secretariat.
\end{abstract}

Key words: Intelligence. Strategic Intelligence. State Intelligence. National State System of Intelligence. State Strategic Intelligence Secretariat.

\title{
O Sistema Nacional de Inteligência do Estado no Uruguai. Lei 19.696 com as modificações introduzidas pela Lei de Consideração Urgente 19.889
}

Resumo: O trabalho aborda o estudo da lei 19.696 e sua emenda 19.889 , lei de consideração urgente, que regulamenta o Sistema de Inteligência do Estado, sob estrito controle e atribuindo importantes propósitos ao seu órgão mais importante, a Secretaria de Inteligência Estratégica.

Palavras-chave: Inteligência. Inteligência estratégica. Inteligência de estado. Sistema Nacional de Inteligência do Estado. Secretaria Estadual de Inteligência Estratégica. 


\section{Introducción al tema}

1.1. La Inteligencia resulta un aspecto de fundamental importancia en la política de seguridad de los Estados, que a lo largo de la historia ha sido vital para la sobrevivencia de las instituciones político-administrativas. Sin embargo, existe la imperiosa necesidad de compaginar seguridad nacional y respeto a los derechos fundamentales y su control efectivo resulta esencial para señalar la línea demarcatoria entre el Estado democrático y el autoritarismo, entre la autoridad ejercida legítimamente y la arbitrariedad política.

En democracia, los servicios de inteligencia no poseen autonomía ni intervienen en la definición de los objetivos de la seguridad nacional, pues ello es competencia del poder político; la política de seguridad, si bien debe ser consensuada, no reviste mayor importancia que el resto de los objetivos y políticas nacionales. Su rol se restringe a la dimensión técnica, esto es, a asesorar al más alto nivel y alertar al poder político sobre posibles fuentes de riesgo para el Estado. Pero siempre será el responsable político quien fije los objetivos de la política de seguridad y consiguientemente, de los servicios de inteligencia (Sansó y Pascual, 2019, pp. 127-128) (Heidenrich, 2007).

Cabe entender por inteligencia "tanto la información como el proceso a través del cual esa información es reunida, analizada, distribuida y usada por los decisores" (Jackson, P. y Siegel, J., 2005, p.3), utilizando diversos medios y recursos tecnológicos, bajo la premisa de que "la comunicación directa en tiempos de crisis era preferible a la comunicación entre intermediarios especializados" (Bull, 1995, p. 172). Quienes realizan esta labor son los Servicios de Inteligencia, a los que referiré seguidamente.

1.2. En Uruguay, la ley 19.696 , en el artículo $3^{\circ}, 1$ literal A), aporta el concepto de Inteligencia, además de definir otros tipos de Inteligencia, como la Militar y la Policial, en los literales D) y E).

$1 \quad$ El artículo $3^{\circ}$ aporta las definiciones para los fines de la ley y de las actividades que regula.

A) Inteligencia: actividad institucional relativa a la recolección, análisis, procesamiento y diseminación de información relevante para los asuntos de seguridad interna y externa del Estado.

B) Contrainteligencia: actividad de Inteligencia cuyo objetivo es detectar, localizar y neutralizar acciones desarrolladas por otros Estados o por personas u organizaciones, que puedan afectar los intereses del Estado, su seguridad interior o la Defensa Nacional.

C) Inteligencia Estratégica: conocimiento elaborado al más alto nivel, necesario para la toma de decisiones, formulación de políticas y elaboración de planes para la consecución de los objetivos nacionales. Refiere a una visión global sobre asuntos políticos, económicos, diplomáticos, ambientales y militares, nacionales e internacionales.

D) Inteligencia Militar: actividad que comprende lo relativo a la obtención, procesamiento, análisis y distribución de información dirigida a preservar la soberanía, la independencia e integridad territorial, la salvaguarda de los recursos estratégicos del país que determine el Poder Ejecutivo y contribuir a preservar la paz de la República.

E) Inteligencia Policial: actividad que comprende lo relativo a la obtención, procesamiento, análisis y distribución de información relativa a la prevención y eventual represión del delito común y el organizado en su calidad de auxiliar de la Justicia, a través de la prevención y represión del delito.

F) Coordinación de Inteligencia: concertación de medios, recursos y actividades, para llevar a cabo una acción común a través del uso de Inteligencia.

G) Canal técnico: herramienta empleada por los órganos integrantes del Sistema Nacional de Inteligencia, para que en forma paralela y simultánea a sus propias dependencias jerárquicas se relacionen entre sí mediante el intercambio de información y la cooperación mutua, con conocimiento del jerarca respectivo y sin perjuicio de las responsabilidades que les pudieren caber.

H) Fuentes: personas, organizaciones, objetos, acciones o documentos de los cuales puede obtenerse información importante para la actividad de inteligencia. Se clasifican en abiertas y cerradas:

1) Fuentes abiertas: son aquellas de las cuales se puede obtener un determinado informe, sin más restricción que la tarea que demanda su obtención.

2) Fuentes cerradas: son aquellas cuyo acceso es restringido y que para la obtención de la información es necesario el uso de medios y procedimientos especiales.

I) Informe: cualquier descripción, detallada o no, de un hecho generador de conocimiento. 
Se la menciona además, dentro de los Cometidos de la Secretaría de Inteligencia Estratégica de Estado (SIEE), en los literales A), B), G) y H).

Conforme lo expresado, el servicio de inteligencia puede definirse como un organismo del Estado que tiene como misión obtener información y difundir inteligencia sobre diversas amenazas, a fin de hacer posible su prevención y facilitar la toma de decisiones por parte de las autoridades de gobierno. Crea un eficaz sistema de información con el fin de suministrar al Estado conocimiento para la comprensión de su entorno, el ajuste de su estrategia, la adopción de medidas de intervención e influencia en la realidad, el desarrollo de operaciones tanto de información como de desinformación y de contrainteligencia, en el terreno de la seguridad y la defensa. Su objetivo es generar información evaluada para los órganos de decisión política, que contribuya a lograr certeza en la toma de decisiones. Es un instrumento de la política exterior (Murillo Zamora, C., 2015, pp. 45 - 46) y de defensa (Berridge y Alan, 2001, p. 93) (Keithly, 2010, pp. 43 - 58) y complementaria a la política de seguridad interior.

1.3. En Uruguay, el marco jurídico que regula los aspectos relativos a la Inteligencia de Estado se encuentra establecido en la ley 19.696, de 29 de octubre de 2018, con las modificaciones introducidas por la ley de urgente consideración (LUC) 19.899, de 9 de julio de 2020.

Los artículos1 a 7 de la ley señalan, sucesivamente, el objeto de la norma (artículo $1^{\circ}$ ), los Principios bajo los cuales se abordarán las actividades de inteligencia (artículo $2^{\circ}$ ), aporta las definiciones de diversos conceptos vinculados con dicha actividad $\left(\right.$ artículo $3^{\circ}$ ), establecen los objetivos de las tareas (artículo $4^{\circ}$ ), los Principios Generales para su actuación (artículo $5^{\circ}$ ), los derechos, deberes y garantías a que ajustarán su funcionamiento, así como las Prohibiciones para los órganos de inteligencia; los artículos 8 a 9 aportan la definición y la integración del Sistema Nacional de Inteligencia de Estado; los artículos 10 y 11 refieren a la creación y funciones de la Secretaría; los artículos 12 a 15 refieren a diversos aspectos relacionados con el Director de la Secretaría y los artículos 16 a 19 a diversos aspectos vinculados al personal de la misma.

Los artículos 20 y 21 refieren a aspectos concretos de actuación, como lo son los procedimientos especiales de obtención de información; los artículos 21 a 23 refieren a aspectos de fundamental importancia, como los controles internos y externos de los órganos de inteligencia, en tanto los artículos 25 a 27, complementarios de los anteriores establecen y regulan el contralor parlamentario.

Los artículos 28 a 37 se refieren a la clasificación, reclasificación, desclasificación, plazo y reserva de la información, así como a diversos tipos de información y a la obligación de los funcionarios de los órganos de inteligencia. 


\section{Del Sistema Nacional de Inteligencia de Estado y de la Secretaría de Inteligencia Estratégica}

\subsection{Del Sistema Nacional de Inteligencia de Estado (Javier, J., 2020)}

2.1.1. Conforme la definición del artículo $8^{\circ}$, en redacción dada por el artículo 118 de la LUC, el Sistema Nacional de Inteligencia de Estado (SNIE) comprende el conjunto de todos los organismos y órganos, independientes entre sí y funcionalmente coordinados, que dirigen y ejecutan actividades específicas de Inteligencia y Contrainteligencia.

La Secretaría de Inteligencia Estratégica de Estado (SIEE), en las condiciones que establezca la reglamentación, ejercerá la dirección técnica de todos los componentes del Sistema Nacional de Inteligencia de Estado que, sin perjuicio de su dependencia orgánica y de sus cometidos específicos, se relacionarán entre sí y cooperarán e intercambiarán información a fin de producir Inteligencia Estratégica, coordinándose todos ellos a través de la Mesa Coordinadora de Inteligencia, que será convocada y presidida por el Director de la SIEE.

El Sistema Nacional de Inteligencia de Estado estará integrado, conforme el artículo 9०, por:

A) La Secretaría de Inteligencia Estratégica de Estado.

B) Los órganos que desarrollan tareas de Inteligencia y Contrainteligencia de los Ministerios del Interior, de Defensa Nacional, de Relaciones Exteriores y de Economía y Finanzas.

C) Los organismos del Estado que, por la información que manejaren o por sus capacidades técnicas, puedan contribuir al propósito del Sistema Nacional de Inteligencia de Estado.

Los Sistemas de Inteligencia tienen por finalidad esencial la de servir a un determinado decisor, mediante la producción de un conocimiento especial, interpretando aquella parte de la realidad sobre la cual producir información, conforme los objetivos planteados en el Plan Nacional de Inteligencia y las necesidades de conocimiento, que luego de incorporado en un documento, será elevado a la autoridad de inteligencia.

2.1.2 Todo Sistema de Inteligencia se integra con dos subsistemas (Ponte, G., 2016, pp. 95 - 96), organizados cada uno como sistemas, cuya conformación responderá a las necesidades a que obedecen. El primero de los subsistemas que conforma a un sistema de inteligencia es aquel que tiene la responsabilidad de conducirlo; es el subsistema que lo dirige; es por ello que se denomina "Órgano de Dirección". En Uruguay, lo es el Director de la Secretaría Estratégica de Estado.

Desarrolla sus actividades dentro de la estructura del sistema y entre sus componentes se encuentran aquellos responsables de planificar, de impartir órdenes, de supervisar la recopilación de información, de procesarla, de producir inteligencia y de archivarla o diseminarla a quien se hubiere determinado, legalmente, que necesita conocer los diferentes productos de conocimiento.

Este Órgano de Dirección funciona como ápice o cumbre estratégica del sistema de inteligencia, en el nivel que se haya establecido legalmente que debe situarse respecto de 
la autoridad que toma las decisiones. Se conforma por aquellas personas encargadas de la responsabilidad general de la organización (sistema), ya sea Poder Ejecutivo, Primer Ministro, Ministro de Seguridad o Interior, según corresponda, además de aquellos funcionarios de alto nivel que se ha determinado que también pueden tener conocimiento del resultado de la acción de inteligencia.

El segundo subsistema es el encargado de realizar todas las demás actividades que desarrolla un sistema de inteligencia; por ello se lo denomina subsistema de los Medios o Elementos de Ejecución pues, generalmente, sus actividades se ejecutan fuera de la infraestructura del sistema.

En suma, el Sistema de Inteligencia Nacional es el conjunto de principios, normas, procedimientos, técnicas, instrumentos, organismos y órganos del Estado funcionalmente vinculados, que bajo la dirección y coordinación de la Secretaría de Inteligencia Estratégica de Estado como ente rector, provee de Inteligencia, particularmente Inteligencia Estratégica, pero también de Inteligencia Militar e Inteligencia Policial, sin perjuicio de la radicada en otras áreas, como la impositiva, la aduanera o la económica y de ser ello necesario, realiza actividades de contrainteligencia en las áreas de su responsabilidad.

Puede definirse el Sistema de Inteligencia, como un complejo funcional de órganos de dirección y medios de ejecución de inteligencia, combinados y armónicamente vinculados, que actuarán de conformidad con las relaciones de comando y funcionales establecidas en cada nivel (Ponte, G., 2016, p. 97). ${ }^{2}$

\subsection{De la Secretaría de Inteligencia Estratégica de Estado}

2.2.1. El artículo 10 de la ley, en redacción dada por el artículo 119 de la LUC, crea la Secretaría de Inteligencia Estratégica de Estado (SIEE) como órgano desconcentrado dependiente del Poder Ejecutivo, actuando el Presidente de la República en acuerdo con los Ministros de Interior, Defensa Nacional, Relaciones Exteriores y Economía y Finanzas. La SIEE se comunicará directamente con los restantes organismos del Estado.

La Secretaría de Inteligencia es un órgano, en cuya cúspide, como órgano de dirección, se encuentra el Director de la Secretaría, conforme el artículo 12, al cual la ley le ha transferido poderes propios de decisión en determinada materia, de naturaleza administrativa (Cajarville, 2012, p. 603) enumerados taxativamente en los artículos 11 y 21 , sin que la jerarquía del Poder Ejecutivo se vea comprometida, pero sí la competencia del jerarca en cuanto a las potestades expresamente transferidas.

Para la designación del Director, el Poder Ejecutivo actuará bajo la forma del Acuerdo (plural), integrado con los titulares de los Ministerios vinculados a la inteligencia y a la defensa interna y externa del país, además de a la actividad económica. Se requiere, además, la venia de la Cámara de Senadores, conforme artículo 187 de la Carta. Para su cese, deberá dictarse por el Poder Ejecutivo el correspondiente acto administrativo,

2 Por "relaciones de comando", deberá entenderse aquellas que existen por cuestiones de autoridad legal (encadenamiento o eslabonamiento jerárquico entre individuos, sistemas y subsistemas); mientras que las "funcionales", son aquellas relaciones formales entre individuos, sistemas y subsistemas que no implican responsabilidad para impartir órdenes, pero sí para coordinar, supervisar o apoyar. 
actuando bajo la forma del Acuerdo (plural) con los Ministros de las carteras que le designan, con la dada cuenta a la Asamblea General, conforme se dispone en el artículo 13.

La misión encomendada al Director de la Secretaría, conforme el inciso $2^{\circ}$ del artículo 10, es la producción de Inteligencia Estratégica, con el fin de asesorar al Poder Ejecutivo. Por tanto, el resultado final del ciclo de inteligencia será la elaboración de esta, que pondrá a disposición del Poder Ejecutivo para que este, como decisor al más alto nivel institucional y político, adopte las decisiones que corresponda.

El Director ocupará el cargo por un plazo máximo de seis años consecutivos y no podrá ser designado nuevamente antes de tres años, contados desde la "finalización" de sus funciones, expresión que sustituyera a la de "término", conforme la redacción dada por el artículo 121 de la LUC 19.889.

También el inciso $3^{\circ}$ de este artículo 12 fue sustituido por el artículo 121 de la LUC, creándose el cargo de Subdirector de la Secretaría, quien subrogará al Director de la SIEE en caso de ausencia o impedimento circunstanciales (esto es, por breve período, como viajes al extranjero o enfermedad $\mathrm{u}$ otro impedimento que le impida el ejercicio del cargo) por un plazo no mayor a ciento ochenta días. En caso de que este también deba ser subrogado, lo será por el funcionario que corresponda (conforme disponía la redacción original), de acuerdo con la estructura interna y el orden jerárquico que determine, en ambos casos, la reglamentación a dictarse.

Conforme el artículo 14, el cargo de Director de la Secretaría de Inteligencia Estratégica de Estado será de dedicación exclusiva e incompatible con cualquier otra actividad.

2.2.2. El artículo 122 de la LUC, como excepción a la incompatibilidad absoluta, permite ahora al Director de la SIEE el ejercicio de la docencia directa en instituciones universitarias o de estudios superiores, públicos o privados como, por ejemplo, en el Centro de Estudios Judiciales del Uruguay, institución de formación y capacitación de los Magistrados Judiciales, o en Centros de Estudios Superiores de las Fuerzas Armadas o Policiales, etc.

La ley 19.696, en el artículo $3^{\circ}$ literal C), define a la Inteligencia Estratégica como "conocimiento elaborado al más alto nivel, necesario para la toma de decisiones, formulación de políticas y elaboración de planes para la consecución de los objetivos nacionales. Refiere a una visión global sobre asuntos políticos, económicos, diplomáticos, ambientales y militares, nacionales e internacionales." Es también referida en el artículo 11, literales D) y E), dentro de los cometidos de la Secretaría de Inteligencia Estratégica de Estado (SIEE).

En suma, se concibe actualmente como un sistema fundamental para la seguridad y la defensa, que tiende a través del análisis de riesgos, amenazas y aún de oportunidades y de un proceso de anticipación estratégica, a aportar claridad para la toma de decisiones al más alto nivel, dentro de un panorama que se presenta confuso, rápidamente cambiante y evolutivo. 


\section{De los Principios Generales de actuación y de las Prohibiciones impuestas a los servicios de inteligencia}

1. El artículo $5^{\circ}$ establece los Principios Generales a los que deberán ajustar su actuación los órganos que integran el Sistema Nacional de Inteligencia para la recolección y tratamiento de la información:

A) Jerarquía: implica la actuación de acuerdo a la subordinación y a la responsabilidad orgánica con ajuste a la regla de Derecho.

B) Eficacia: significa que existirá una adecuada relación entre los medios empleados y la calidad y oportunidad del producto obtenido.

C) Especificidad: refiere a que los fondos asignados a los órganos, incluyendo los reservados, serán empleados exclusivamente para el cumplimiento de los fines debidos.

D) Juridicidad: refiere a la estricta observancia de la Constitución, los tratados internacionales, las leyes y demás fuentes del ordenamiento jurídico, evitando en todo caso las actividades invasivas de la privacidad de las personas.

E) Ponderación: implica que la información que se requerirá será la necesaria y solo se diseminará la tendiente al cumplimiento de los cometidos de cada uno de los órganos integrantes del Sistema, de acuerdo a sus respectivas reglamentaciones, a las disposiciones de la Secretaría de Inteligencia Estratégica de Estado y a esta ley. Por lo tanto, contravendrá este principio el empleo de la información del Sistema en beneficio específico de personas, organizaciones privadas, partidos políticos $\mathrm{u}$ otras de cualquier naturaleza y finalidad, quedando estos casos sujetos a las acciones civiles, administrativas y penales que pudieren corresponder.

Los principios generales resultan fundamentales para el desarrollo de la actividad de inteligencia y los órganos que integran el Sistema Nacional de Inteligencia deben observarlos en la recolección y el tratamiento de la información. Son los de Jerarquía, Eficacia, Especificidad, Juridicidad y Ponderación, respecto de cada uno de los cuales la ley, además de enumerarlos, señala cuál es su significado en el caso concreto de los servicios de inteligencia.

2.2.3. Solo referiré ahora a dos principios, los de Jerarquía y de Coordinación. El de Jerarquía, consagrado en el literal A) del artículo $5^{\circ}$ de la ley, refiere al deber de obediencia del funcionario, corolario de la subordinación propia de toda organización basada en el referido principio.

Por esta vía, se asegura la unidad de acción de la actividad administrativa en la prosecución y el logro eficaz de sus fines (Prat, 1978, p. 116).

El Principio de Coordinación, establecido en el artículo 8 inciso $3^{\circ}$ de la ley como cometido específico del Director de la SIEE, que ejerce a través de la Mesa Coordinadora de Inteligencia (que convocará y presidirá), consiste en brindar coherencia funcional a todo el conjunto de organismos y órganos, que son independientes entre sí, pero que tienen en común que dirigen y ejecutan actividades específicas de inteligencia y de contrainteligencia, conforme lo establecido en el artículo $8^{\circ}$ inciso $1^{\circ}$. 
Se trata de coordinar, dando coherencia, al ejercicio de competencias similares de órganos diversos, tendientes al logro de un objetivo común, evitando la duplicación de esfuerzos y la toma de acciones contradictorias por las agencias de inteligencia, en relación con una determinada materia u objetivo perseguido.

El artículo $3^{\circ}$ literal F) de la ley 19.696, define a la Coordinación de Inteligencia como: "concertación de medios, recursos y actividades, para llevar a cabo una acción común a través del uso de Inteligencia.".

La ley reafirma este principio, pues si bien reconoce la independencia orgánica y de sus cometidos específicos, dispone que los componentes del Sistema deberán relacionarse entre sí, cooperando e intercambiando información, bajo la coordinación de la Secretaría, conforme disponga la reglamentación.

El artículo 11 literal C) de la ley 19.696 reafirmaba este principio de coordinación, pero la ley de urgente consideración (LUC) 19.889, en el artículo 120, sustituyó la expresión "coordinar" por "dirigir técnicamente" el funcionamiento del Sistema Nacional. A ello me referiré en el Capítulo 5.

El inciso $3^{\circ}$ del artículo $8^{\circ}$ crea el órgano que organizará dicha cooperación, relacionamiento y colaboración, la Mesa Coordinadora de Inteligencia, que presidirá el Director de la Secretaría.

Deberá asegurarse el flujo de información entre las diferentes áreas de la inteligencia, de forma de evitar que se establezcan verdaderos "compartimientos estancos" de información, que impidan apreciar un cuadro global de la situación, intercambiando información, de ser ello necesario, con los servicios de inteligencia de otras naciones. ${ }^{3}$

2.2.4. El artículo $7^{\circ}$ establece las Prohibiciones para los órganos de inteligencia. Expresamente dispone en el inciso $1^{\circ}$ que ningún órgano de Inteligencia tendrá facultades compulsivas y en cuatro numerales, señala las actividades que les estará especialmente prohibido cumplir:

1) Realizar tareas represivas; cumplir, por sí, funciones policiales o de investigación criminal, salvo que dicha actividad se encuentre dentro de sus cometidos legales específicos o mediante requerimiento judicial en el marco de una causa concreta.

2) Intervenir en la actividad política, social o económica del país, en su política exterior o en la vida interna de los partidos políticos.

3) Influir de cualquier forma en la opinión pública, en personas, medios de difusión, asociaciones o agrupaciones de cualquier naturaleza.

4) Revelar o divulgar cualquier tipo de información adquirida en ejercicio de sus funciones, fuera de lo dispuesto en esta ley, salvo que mediare disposición judicial.

El artículo 7, numeral 1), establece que los servicios de inteligencia tienen expresamente prohibido realizar tareas represivas o acciones de tipo policial o de investigación criminal. Ello resulta acertado, pues tales actividades, además de ser violatorias de los derechos

3 La importancia de la coordinación radica precisamente en ello, en impedir que un sector de la inteligencia posea una información y no la comparta con otro, poniendo en riesgo de esa forma la detección de eventuales peligros o amenazas al manejar la información como propia o exclusiva y no permitir que ella sea evaluada o contrastada con otras informaciones relacionadas que puedan provenir de otras fuentes o sectores de la inteligencia. 
de las personas, desnaturalizarían sus fines, desconociendo el Fin Debido que debe perseguir, salvo que la ley lo haya establecido como uno de sus cometidos específicos u objetivos de protección y defensa de los intereses nacionales (conforme el artículo $4^{\circ}$ ), o ello le haya sido requerido judicialmente, cumpliendo procedimientos especiales que puedan afectar la libertad y privacidad de los ciudadanos y el requerimiento provenga de los Juzgados Letrados de Primera Instancia en lo Penal Especializados en Crimen Organizado, conforme establece el artículo 20 , inciso $1^{\circ}$ de la ley.

2.2.5. Conforme el numeral 2 les está vedado intervenir en la actividad política, en la vida interna de los partidos políticos o en las áreas sociales, económicas, o en las relaciones internacionales, la opinión pública o en los medios de comunicación.

El numeral 3 les prohíbe absolutamente influir en la opinión pública, en personas, medios de difusión, asociaciones o agrupaciones de cualquier naturaleza. Atento a ello, no podrán revelar los "datos sensibles", referidos en el artículo $4^{\circ}$ literal E) de la ley $18.331{ }^{4}$ de Acceso a la Información Pública; a vía de ejemplo, se les prohíbe discriminar en sus informes o información a grupos étnicos, raciales o religiosos, recopilar datos sobre la vida privada de las personas, sobre sus opiniones o negocios, o relacionadas con toda actividad lícita que hayan realizado, conforme la ley.

El numeral $4^{\circ}$ y último, prohíbe a los miembros de los servicios de inteligencia, revelar información sobre los ciudadanos y las diferentes organizaciones que desarrollan actividades en el país, salvo que exista expresa autorización judicial, debiendo remitirnos a lo ya expresado al respecto.

En este caso, resulta aplicable el artículo 132 numeral 3 del Código Penal, lo que referiré en el Capítulo 5.

Se prohíbe, además, conforme el artículo 28 de la Constitución, toda intervención telefónica, postal o en sentido amplio, de cualquier medio de transmisión de datos, debiendo estarse a lo que establecieren las leyes por razones de interés general y vale reiterar, previa autorización judicial expresa.

2.2.6. La ley establece en el artículo $1^{\circ}$, que la actividad de inteligencia tiene por objeto establecer y regular el Sistema Nacional de Inteligencia de Estado (SNIE).y sus normas generales, principios, limitaciones y garantías se aplicarán a todas las actividades de inteligencia que realicen los órganos que forman parte del mismo.

El artículo $2^{\circ}$ establece que los órganos integrantes del Sistema Nacional de Inteligencia desarrollarán sus actividades bajo el más estricto cumplimiento de la Constitución de la República y de los principios del régimen democrático republicano de gobierno, con pleno respeto a los derechos humanos y dentro del marco de la Política Nacional de Inteligencia, conforme lo dispuesto en el artículo $6^{\circ}$ de esta ley y por tanto, respetando los derechos, deberes y garantías.

Cabe mencionar que la ley comete al Poder Ejecutivo, en el artículo $3^{\circ}$ inciso $1^{\circ}$, fijar la Política Nacional de Inteligencia (PNI), a fin de contribuir a facilitar la toma de decisiones políticas al más alto nivel, comprometiendo a los poderes públicos, así como a todas 
las instituciones estatales en un esfuerzo integrador con las diversas organizaciones o instituciones que puedan cooperar a sus fines (Holzmann y Gallardo, 1997, p. 118).

Deberá definir las bases del Sistema Nacional de Inteligencia, cuya misión principal es asesorar al más alto nivel en el proceso de toma de decisiones político-estratégicas.

Ese es el objetivo del Plan Nacional de Inteligencia, referido como el cometido prioritario en el literal A) del artículo 11 de la ley 19.696, que deberá formular la Secretaría para conocimiento y aprobación del Poder Ejecutivo, dentro del marco de la Política Nacional de Inteligencia, como política de Estado, que permita la implementación de una Planificación de Inteligencia, que defina los objetivos operacionales en un período determinado de tiempo y la misión general de todos los organismos y órganos que integran el Sistema (independientes entre sí, pero funcionalmente coordinados por la Secretaría). Se trata de establecer "hacia dónde va" la actividad de inteligencia.

2.2.7. El artículo $6^{\circ}$ de la ley, en el inciso $1^{\circ}$ establece, con acierto, que el funcionamiento del Sistema Nacional de Inteligencia de Estado y las actividades de sus integrantes deberán ajustarse estrictamente a las disposiciones contenidas en la Sección II de la Constitución de la República, a las Leyes y Convenios internacionales en materia de protección a los derechos humanos y garantías de sus habitantes.

La ley señala que la actuación de todos los órganos de inteligencia (Militar, Policial, o que dirijan o ejecuten actividades específicas de inteligencia y contrainteligencia (aduanera, económica, etc., conforme el inciso $1^{\circ}$ del artículo $8^{\circ}$ ) deberá desarrollarse con base en el respeto a los Principios Generales para la recolección y tratamiento de la información establecidos en el artículo $5^{\circ}$, a los derechos, deberes y garantías consagrados en la Sección II de la Constitución de la República, así como a las leyes y convenios internacionales en materia de protección de los derechos humanos y garantías de sus habitantes, conforme el artículo $6^{\circ}$ inciso $1^{\circ}$ y las Prohibiciones expresamente establecidas en el artículo 7 de la ley y ya referidas.

Conforme el inciso $2^{\circ}$ del artículo $6^{\circ}$, el Poder Ejecutivo establecerá los procedimientos necesarios para garantizar a cualquier persona un recurso efectivo de defensa contra todas las actividades y organismos que integran el Sistema Nacional de Inteligencia de Estado.

Ello se encuentra conforme con lo dispuesto en el artículo 25 de la Convención Americana de Derechos Humanos, Pacto de San José de Costa Rica, ${ }^{5}$ en cuanto a que reconoce una garantía secundaria o jurisdiccional, que más allá de su función jurídica, ha recibido diferentes denominaciones como "acceso a la justicia", "derecho a la jurisdicción", "derecho a la protección judicial" o "derecho de peticionar".

2.2.8. En otro orden, el artículo $6^{\circ}$ de la ley 19.696, en el inciso $3^{\circ}$, establece que cada organismo del sistema deberá adoptar las medidas conducentes para la prevención de todo abuso o excesos en el ejercicio de las atribuciones y facultades que la ley otorga, así

5 Artículo 25. Protección Judicial. 1.Toda persona tiene derecho a un recurso sencillo y rápido o a cualquier otro recurso efectivo ante los jueces o tribunales competentes, que la ampare contra actos que violen sus derechos fundamentales reconocidos por la Constitución, la ley o la presente Convención, aun cuando tal violación sea cometida por personas que actúen en ejercicio de sus funciones oficiales.2. Los Estados partes se comprometen: a) a garantizar que la autoridad competente prevista por el sistema legal del Estado decidirá sobre los derechos de toda persona que interponga tal recurso; b) a desarrollar las posibilidades de recurso judicial, y c) a garantizar el cumplimiento, por las autoridades competentes, de toda decisión en que se haya estimado procedente el recurso. 
como dar estricto cumplimiento a lo que establece la normativa vigente sobre la gestión y uso de los datos personales.

Ello refiere al estricto contralor interno que debe existir dentro de la organización de inteligencia. Debe vincularse con lo expresado al comentarse el artículo $2^{\circ}$ y con la obligación de los legisladores de cumplir con las normas de seguridad para proteger la información, aún luego de su cese en las funciones, establecida en el artículo 27 inciso $1^{\circ}$ de la ley.

Los Objetivos de la ley se señalan en el artículo $4^{\circ}$. Conforme este, las tareas de inteligencia se desarrollarán con ajuste a los objetivos de protección y defensa de los intereses estratégicos nacionales, de acuerdo a la Constitución de la República, las leyes y a los principios generales del Derecho (debe recordarse que en Uruguay estos son recibidos por el artículo 72 de la Carta), con especial aplicación de los principios de jerarquía, eficacia, especificidad, juridicidad y ponderación, recogidos en el artículo $5^{\circ}$ de la ley.

Resulta fundamental en este contexto, el diseño de la Política de Defensa, estrechamente unida a la Política Nacional de Inteligencia, conforme lo establecido en la Ley Marco de Defensa Nacional 18.650, de 19 de febrero de 2010, que en los artículos $1^{\circ}$ y $2^{\circ}$ aporta el concepto de Defensa Nacional y señala sus características, así como el marco estratégico para la implementación de una Política en tal sentido (Javier, 2015) y consecuentemente, de una Política Militar de Defensa (Javier, 2016), que deberá establecer a su vez, siguiendo los lineamientos de la Política de Defensa Nacional, la nueva doctrina del empleo de los medios militares por parte de las Fuerzas Armadas. ${ }^{6}$

2.2.9. La elaboración de inteligencia sigue un proceso denominado "ciclo de la inteligencia", en el cual se debe distinguir entre el objeto (la información), los medios posibles para su obtención y el producto (la inteligencia), que se entrega a la autoridad a la que corresponde decidir, luego de evaluar la fiabilidad de los datos obtenidos, analizarlos, integrarlos e interpretarlos.

Este ciclo se retroalimenta constantemente y genera nueva información en base a la cual los decisores políticos reajustarán su agenda, conforme a las amenazas y riesgos identificados. Así, si un grupo terrorista amenazare gravemente la seguridad nacional y se solicitare un informe de inteligencia que confirme o no esa suposición y la información producida comprobase que dicho peligro es inexistente, ese grupo terrorista perdería importancia dentro de la agenda política. También es válida la hipótesis inversa, lo cual llevaría a que ese asunto cobrara la mayor importancia.

Habitualmente, el proceso de inteligencia consta de cinco etapas, que no responden necesariamente a una secuencia:

1. Dirección y Planificación. Los destinatarios de la inteligencia, por lo general, decisores al más alto nivel político, plantean una serie de demandas a los responsables del servicio de inteligencia, fijando un objetivo a ser alcanzado en materia de seguridad o política exterior, que son convertidas en requerimientos específicos por los 
órganos de dirección del servicio, que a partir de ellas asignan tareas, distribuyen recursos y despliegan su actividad.

Planificación. Consiste en determinar las áreas de interés estratégico del servicio de inteligencia y las necesidades de información concretas requeridas, que se establecen mediante la identificación y clasificación en niveles de prioridad de los ámbitos de actuación del servicio. Posteriormente, este traduce esas prioridades en necesidades generales de información, clasificadas en diversas áreas, fundamentalmente, de 3 tipos, según el momento de su utilización: básica, actual y estimativa.

2. Obtención y Recolección. En esta fase se busca y recopila información a través de diversos medios, que pueden ser tecnológicos, humanos, documentales, provenir de fuentes abiertas o cerradas, etc. Sólo se recopila información, en bruto, sin procesar, tanto de fuentes secundarias, más accesibles, aunque menos fiables, como de fuentes primarias, con mayor dificultad de acceso, pero con información de calidad.

3. Procesamiento y Explotación. Elaboración. En esta fase se traslada toda esa información recopilada a un grupo de analistas, que la evalúan, analizan, integran e interpretan con la intención de que al final resulte una información procesada que, siguiendo las pautas establecidas en el objetivo político, le sea útil a los decisores de alto nivel para resolver en base a una información fiable y con el mayor detalle posible.

4. Análisis y producción. En esta etapa se extrae información, con precisión y rapidez, de los datos obtenidos, que estimule, por inducción, a la construcción de conocimiento. Se marca la frontera entre información e inteligencia, separándose los órganos responsables de la obtención de información de los encargados de su elaboración en función de sus áreas de actuación (nacional, internacional, etc.) mediante el trabajo de analistas que aplican todo su capital intelectual.

Posteriormente, se procede a la interpretación de los datos, recogiéndose el resultado en un documento, cuya tipología (informe, dossier, resumen, estadística, etc.) depende de la mayor o menor elaboración de la información que contiene.

5. Comunicación. Difusión. Esta etapa consiste en la distribución y puesta a disposición del demandante del documento creado con la información obtenida, procesada e interpretada, de modo seguro.

6. Evaluación continua. La comunicación de informes de inteligencia no supone el final del proceso, sino que resulta necesario analizar las reacciones de los usuarios ante la información suministrada, identificar los objetivos cumplidos con las decisiones adoptadas en base a ellas y valorar la importancia que la información ha tenido en el logro de esos objetivos, inclusive replanteándose las conclusiones obtenidas. 


\section{La clasificación de la información del Sistema Nacional de Inteligencia de Estado. Las modificaciones introducidas por la ley de Urgente Consideración 19.899}

4.1. Conforme el artículo 28 inciso $1^{\circ}$ de la ley 19.696, los órganos del Sistema Nacional de Inteligencia de Estado, de acuerdo con lo previsto por el literal F) del artículo 11,7 adoptarán procedimientos estandarizados para clasificar información, reclasificarla o desclasificarla, acorde a la sensibilidad y al compromiso a la seguridad que pueda implicar su inapropiada divulgación, de conformidad con lo dispuesto por la ley 18.381, de Acceso a la Información Pública, de 17 de octubre de 2008.

Conforme la remisión legal, serán aplicables las hipótesis previstas en el artículo $9^{\circ}$ de la ley de Derecho de Acceso a la Información Pública ${ }^{8}$ para clasificar como Reservada una información.

Deberá incluirse la documentación que suscribirá el personal de los órganos del Sistema Nacional de Inteligencia de Estado y las personas ajenas al mismo, de corresponder, para acceder a un nivel determinado de autorización de manejo de información clasificada, basado en el principio de seguridad denominado "Necesidad de Conocer".

Este principio, conforme el inciso $2^{\circ}$ del artículo 28, implica que la habilitación para acceder a una determinada información clasificada estará determinada por la necesidad de que la misma sea conocida para poder desarrollar su trabajo, no siendo suficiente la función, cargo, grado o jerarquía de quien la requiere.

El citado principio, conocido como need to know (NTK), se basa en que el poseedor de una información decide sobre su difusión sólo conforme las credenciales del presunto destinatario, con base en dos preguntas contestadas sólo por dicho poseedor: 1. ¿tiene o no el destinatario necesidad de conocer? Y 2. ¿tiene acreditado el nivel de acceso necesario para ello?

7 Artículo 11 literal F): Formular normas y procedimientos estandarizados comunes para todos los órganos del Sistema Nacional de Inteligencia de Estado

8 Ley 18.381, artículo 9. (Información reservada).- Como información reservada podrá clasificarse aquella cuya difusión pueda: Artículo 11 literal F):

A) Comprometer la seguridad pública o la defensa nacional.

B) Menoscabar la conducción de las negociaciones o bien, de las relaciones internacionales, incluida aquella información que otros estados u organismos internacionales entreguen con carácter de reservado al Estado uruguayo.

C) Dañar la estabilidad financiera, económica o monetaria del país.

D) Poner en riesgo la vida, la dignidad humana, la seguridad o la salud de cualquier persona.

E) Suponer una pérdida de ventajas competitivas para el sujeto obligado o pueda dañar su proceso de producción.

F) Desproteger descubrimientos científicos, tecnológicos o culturales desarrollados o en poder de los sujetos obligados.

G) Afectar la provisión libre y franca de asesoramientos, opiniones o recomendaciones que formen parte del proceso deliberativo de los sujetos obligados hasta que sea adoptada la decisión respectiva, la cual deberá estar documentada.

La clasificación de la información reservada deberá realizarse por el sujeto obligado en el momento en que esta se genere, obtenga o modifique, mediante resolución debidamente fundada y motivada, en la que se demuestre la existencia de elementos objetivos que permitan determinar que la divulgación de la misma genera un riesgo claro, probable y específico de daño al interés público protegido, de acuerdo con las excepciones referidas en el presente artículo.

Excepcionalmente, la información podrá clasificarse como reservada en el momento en que se reciba una solicitud de acceso a la misma. En este caso, la resolución fundada que disponga la clasificación de la información deberá remitirse en el plazo de cinco días hábiles a la Unidad de Acceso a la Información Pública, la que en ejercicio de su cometido de control, solicitará al sujeto obligado su desclasificación si la misma no se ajustare a lo dispuesto en el presente artículo. En cualquier caso, el plazo de reserva comenzará a computarse a partir de que la información pudo ser clasificada.

En todo momento, la Unidad de Acceso a la Información Pública podrá tener acceso a la información clasificada para evaluar la regularidad de su clasificación. 
4.2. El principio, prevalente en EEUU y en las agencias de inteligencia europeas, ha recibido fuertes críticas (Del Pozo, 2019, p. 436). Se ha expresado que convierte al que ha obtenido la información en «dueño» de ella, con voluntad para decidir sobre su distribución, independientemente de su visión del panorama general, abandonando el rol de contribuir a la tarea colectiva de construir inteligencia a partir de diversas informaciones independientes.

Se habla, por tanto, que el NTK debe ser reemplazado, para así facilitar el cotejo, contraste, o complemento de las informaciones dudosas o incompletas con otros elementos, sin vulnerar su confidencialidad, que permita que la información fluya en beneficio de la seguridad, pero sin comprometer aquellos factores que podrían perjudicar las posteriores operaciones de los servicios.

Así surge la responsabilidad de compartir (responsibility to share, RTS), que implica que la persona en posesión de una información se encuentra obligada a distribuirla a cualquiera que pueda legítimamente usarla y si algún daño se produce por no distribuirla, el que lo ha impedido será considerado como responsable (Del Pozo, 2019, p. 437).

4.3. En otro orden el artículo 29 de la ley 19.696 prescribe que se considerarán reservados y de circulación restringida, para todos los efectos legales, de acuerdo al artículo $9^{\circ}$ de la referida ley 18.381, los antecedentes, las informaciones y los registros que obren en poder de los órganos que conforman el SNIE y de su personal, cualquiera que sea su cargo, así como aquellos otros antecedentes de los que el personal de tales órganos, por cualquier razón, tome conocimiento en el desempeño de sus funciones.

La LUC 19.889, en el artículo 125, modificó la denominación de este artículo 29, agregándole a "información reservada y restringida", la expresión "e información secreta", enfatizando en uno de los aspectos que más caracterizan a los servicios de inteligencia: el secreto, como nueva forma de catalogar la información colectada y que será luego procesada en el referido "ciclo de la inteligencia".

Agrega al artículo un inciso $2^{\circ}$, que establece que elementos, documentales o no, se considerarán secretos, así como a qué órgano de inteligencia le corresponde asignar tal clasificación. Se considerarán secretos los actos, documentos, registros, actividades y cualquier otro material o insumo de los órganos que integran el Sistema Nacional de Inteligencia de Estado, cuya difusión pueda provocar daño a los acuerdos internacionales de cooperación en materia de inteligencia, a la independencia del Estado respecto de otros Estados u organismos internacionales y a las relaciones con estos.

"Secreto", es el estado por el cual el titular de un interés actual y relevante jurídicamente, determina razonablemente, de acuerdo a la naturaleza del objeto de su conocimiento que el conocimiento del mismo deba permanecer vedado a todos, o reservado sólo a determinadas personas (Bayardo Bengoa, F., 1961, pp. 16 - 27). La "confidencialidad", es sólo una de las formas de expresión del secreto como lo es, asimismo, la reserva. 
Deberá recordarse lo dispuesto en los artículos 8 a 12 de la ley $18.381,{ }^{9}$ de derecho de acceso a la información pública, de 17 de octubre de 2008 (Duran Martínez, 2012), sin perjuicio de lo que seguidamente se expresará.

4.4. La parte final del inciso $3^{\circ}$ del artículo 29, dispone que dicha clasificación será realizada por el Director de la Secretaría y sólo se podrá acceder a la misma mediante resolución fundada del Presidente de la República, actuando en Consejo de Ministros.

Esta facultad conferida al Director de la Secretaría resulta controversial, pues este decidirá, discrecionalmente, cuál información merece tal clasificación, sin control alguno y sin que la ley establezca algún requisito que deba observar como fundamento de la decisión. En caso de que quiera desclasificarse la misma, sólo el órgano responsable máximo de inteligencia del país, el Poder Ejecutivo en Consejo de Ministros, dictando una resolución fundada, conforme impone el Estado de Derecho, podrá dejar sin efecto la clasificación de secreta y revelar su contenido.

Conforme la modificación legal, se diferencia ahora nítidamente entre, por un lado, información clasificada de circulación restringida, en el marco de lo previsto en el artículo $9^{\circ}$ de la ley 18.381 y por otro, información clasificada como Secreta, así declarada conforme el inciso $3^{\circ}$, parte final, del artículo 29.

9 Artículo 8. (Excepciones a la información pública).- Las excepciones a la información pública serán de interpretación estricta y comprenderán aquellas definidas como secretas por la ley y las que se definan seguidamente como de carácter reservado y confidencial.

Artículo 9. (Información reservada).- Como información reservada podrá clasificarse aquella cuya difusión pueda:

A) Comprometer la seguridad pública o la defensa nacional.

B) Menoscabar la conducción de las negociaciones o bien, de las relaciones internacionales, incluida aquella información que otros estados u organismos internacionales entreguen con carácter de reservado al Estado uruguayo.

C) Dañar la estabilidad financiera, económica o monetaria del país.

D) Poner en riesgo la vida, la dignidad humana, la seguridad o la salud de cualquier persona.

E) Suponer una pérdida de ventajas competitivas para el sujeto obligado o pueda dañar su proceso de producción.

F) Desproteger descubrimientos científicos, tecnológicos o culturales desarrollados o en poder de los sujetos obligados.

G) Afectar la provisión libre y franca de asesoramientos, opiniones o recomendaciones que formen parte del proceso deliberativo de los sujetos obligados hasta que sea adoptada la decisión respectiva, la cual deberá estar documentada.

La clasificación de la información reservada deberá realizarse por el sujeto obligado en el momento en que esta se genere, obtenga o modifique, mediante resolución debidamente fundada y motivada, en la que se demuestre la existencia de elementos objetivos que permitan determinar que la divulgación de la misma genera un riesgo claro, probable y específico de daño al interés público protegido, de acuerdo

con las excepciones referidas en el presente artículo.

Excepcionalmente, la información podrá clasificarse como reservada en el momento en que se reciba una solicitud de acceso a la misma. En este caso, la resolución fundada que disponga la clasificación de la

información deberá remitirse en el plazo de cinco días hábiles a la Unidad de Acceso a la Información Pública, la que en ejercicio de su cometido de control, solicitará al sujeto obligado su desclasificación si la misma no se ajustare a lo dispuesto en el presente artículo. En cualquier caso, el plazo de reserva comenzará a computarse a partir de que la información pudo ser clasificada.

En todo momento, la Unidad de Acceso a la Información Pública podrá tener acceso a la información clasificada para evaluar la regularidad de su clasificación.

Artículo 10. (Información confidencial).- Se considera información confidencial:

I) Aquella entregada en tal carácter a los sujetos obligados, siempre que:

A) Refiera al patrimonio de la persona.

B) Comprenda hechos o actos de carácter económico, contable, jurídico o administrativo, relativos a una persona física o jurídica, que pudiera ser útil para un competidor.

C) Esté amparada por una cláusula contractual de confidencialidad.

II) Los datos personales que requieran previo consentimiento informado.

Tendrán el mismo carácter los documentos o secciones de documentos que contengan estos datos.

Artículo 11. (Período de reserva).- La información clasificada previamente como reservada, permanecerá con tal carácter hasta un período de quince años desde su clasificación. La información reservada será desclasificada cuando se extingan las causas que dieron lugar a su clasificación. Sólo se ampliará el período de reserva sobre cierta documentación cuando permanezcan y se justifiquen las causas que le dieron origen. (cursiva en el texto del autor).

Artículo 12. (Inoponibilidad en casos de violaciones a los derechos humanos).- Los sujetos obligados por esta ley no podrán invocar ninguna de las reservas mencionadas en los artículos que anteceden cuando la información solicitada se refiera a violaciones de derechos humanos o sea relevante para investigar, prevenir o evitar violaciones de los mismos. 
Tal clasificación de secreta, con base legal, se encuentra legalmente admitida por el artículo $8^{\circ}$ de la ley $18.381,{ }^{10}$ constituyendo una de las excepciones al libre acceso a la información pública. ${ }^{11}$

4.5. Una cuestión de importancia que plantea la modificación legal, es la relativa al impacto de la reserva impuesta por el artículo 29 y la calificación legal de secretos, establecida por el referido inciso $3^{\circ}$ parte final del artículo 29 , incorporada por la Ley 19.889 , que viene de hacerse referencia y lo establecido en los artículos 25 a 27 de la ley $18.331,{ }^{12}$ de 11 de agosto de 2008, de Protección de Datos Personales.

El artículo 25 establece que quedan comprendidas dentro de lo establecido en la ley 18.331 las bases de datos de las fuerzas armadas, organismos policiales y "servicios de inteligencia" y excluye el consentimiento del titular de los datos en cuanto a su utilización en aquellos supuestos y categoría de datos que resulten necesarios para el estricto cumplimiento de las misiones legalmente asignadas para la defensa nacional, la seguridad pública o para la represión de los delitos.

Debe recordarse que la ley 18.315, de Procedimiento Policial, de 5 de julio de 2008, en los artículos 33 y 34, autoriza a la Policía Nacional a llevar registros y archivos de información calificada, que sólo puede ser revelada por orden de la Justicia competente Javier, J., 2008, pp. 45 - 50).

10 Ley 18.381, artículo 8. (Excepciones a la información pública).- Las excepciones a la información pública serán de interpretación estricta y comprenderán aquellas definidas como secretas por la ley y las que se definan seguidamente como de carácter reservado y confidencial. (cursivas en el texto, del autor).

11 Debe recordarse que el artículo 15 inciso $2^{\circ}$ de la ley 16.698, de 25 de abril de 1995, relativa a las Comisiones Parlamentarias (de investigación), faculta al Poder Ejecutivo para declarar secretos asuntos del Ministerio de Economía y Finanzas, del Ministerio de Defensa Nacional, del Ministerio del Interior y del Ministerio de Relaciones Exteriores.

Esta facultad, de carácter excepcional y sumamente discrecional, conferida al Poder Ejecutivo, deberá ser comunicada al Presidente de la Cámara que hubiere designado la Comisión (investigadora), o en su caso, al de la Comisión Permanente.

La norma no aclara cual es el fundamento jurídico que respalda la decisión del Poder Ejecutivo de declarar secretos "asuntos" (la materia asignada por la Constitución, la ley o los reglamentos) de la competencia de los Ministerios referidos, vinculados a los intereses estratégicos del país. Claramente no lo es la Teoría del Acto de Gobierno, atento a lo expresado en el inciso $1^{\circ}$, ni tampoco señala qué efectos o con qué consecuencias se realiza tal comunicación. Lo cierto es que la investigación dispuesta no contará entonces con la colaboración del Poder Ejecutivo y por tanto, puede concluirse, que sus resultados serán muy limitados. 12 Ley 18.331. Artículo 25. Base de datos correspondientes a las Fuerzas Armadas, Organismos Policiales o de Inteligencia.Quedarán sujetos al régimen de la presente ley, los datos personales que por haberse almacenado para fines administrativos, deban ser objeto de registro permanente en las bases de datos de las fuerzas armadas, organismos policiales o de inteligencia; y aquellos sobre antecedentes personales que proporcionen dichas bases de datos a las autoridades administrativas o judiciales que los requieran en virtud de disposiciones legales.

El tratamiento de datos personales con fines de defensa nacional o seguridad pública por parte de las fuerzas armadas, organismos policiales o inteligencia, sin previo consentimiento de los titulares, queda limitado a aquellos supuestos y categoría de datos que resulten necesarios para el estricto cumplimiento de las misiones legalmente asignadas a aquéllos para la defensa nacional, la seguridad pública o para la represión de los delitos. Las bases de datos, en tales casos, deberán ser específicas y establecidas al efecto, debiendo clasificarse por categorías, en función de su grado de fiabilidad.

Los datos personales registrados con fines policiales se cancelarán cuando no sean necesarios para las averiguaciones que motivaron su almacenamiento. (cursivas en el texto, del autor).

Artículo 26. Excepciones a los derechos de acceso, rectificación y cancelación. - Los responsables de las bases de datos que contengan los datos a que se refieren los incisos segundo y tercero del Artículo anterior podrán denegar el acceso, la rectificación o cancelación en función de los peligros que pudieran derivarse para la defensa del Estado o la seguridad pública, la protección de los derechos y libertades de terceros o las necesidades de las investigaciones que se estén realizando.

Los responsables de las bases de datos de la Hacienda Pública podrán, igualmente, denegar el ejercicio de los derechos a que se refiere el inciso anterior cuando el mismo obstaculice las actuaciones administrativas tendientes a asegurar el cumplimiento de las obligaciones tributarias y, en todo caso, cuando el titular del dato esté siendo objeto de actuaciones inspectivas. El titular del dato al que se deniegue total o parcialmente el ejercicio de los derechos mencionados en los incisos anteriores podrá ponerlo en conocimiento del Órgano de Control, quien deberá asegurarse de la procedencia o improcedencia de la denegación. (cursivas en el texto, del autor).

Artículo 27. Excepciones al derecho a la información. - Lo dispuesto en la presente ley no será aplicable a la recolección de datos, cuando la información del titular afecte a la defensa nacional, a la seguridad pública o a la persecución de infracciones penales. (cursiva en el texto, del autor). 
El artículo 26 de la ley 18.331, en referencia a los incisos $2^{\circ}$ y $3^{\circ}$ del artículo 25, dispone que los referidos organismos podrán denegar el acceso, la rectificación o cancelación en función de los peligros que pudieran derivarse para la defensa del Estado o la seguridad pública, la protección de los derechos y libertades de terceros o las necesidades de las investigaciones que se estén realizando.

El artículo 27 de la ley 18.331 excluye también del acceso a la "recolección de datos" en caso de que la información del titular afecte a la defensa nacional, a la seguridad pública o a la persecución de infracciones penales. De tal forma, se las excluye del "ciclo de la inteligencia" a la fase de recolección, de recopilación de información, a fin de corroborar si existe una amenaza o peligro, información aún sin procesar y que podría, eventualmente, afectar a una persona, de los derechos de acceso, rectificación y cancelación, consagrados en la ley 18.331.

Así, si un ciudadano desea conocer cuál es la información que los servicios de inteligencia han recopilado a su respecto, salvo en las excepciones legales, como la relativa a los derechos humanos e incumplimiento de las disposiciones de la Sección II de la Constitución, establecida en el artículo 33 de la ley, recogiendo en parte la excepción establecida en el artículo 12 de la ley 18.331, ello no será posible, al menos, en dicha etapa del ciclo de inteligencia.

La modificación legal es categórica. Por tanto, parecería no ser aplicable, fuera de las hipótesis previstas en los literales referidos en el artículo $9^{\circ}$ de la ley 18.381, la "prueba del daño", establecida en el artículo 25 del decreto reglamentario $232 / 010,{ }^{13}$ de 2 de agosto de 2010.

4.6. El artículo 30 de la ley refiere a la información clasificada eximida de la clasificación. Establece que los estudios e informes que elaboren los órganos de inteligencia solo podrán eximirse de la clasificación que se les haya asignado, con la autorización del jerarca, de acuerdo al mencionado artículo $9^{\circ}$ de la ley 18.381.

Respecto de los funcionarios de los órganos de inteligencia, el artículo 31 establece que los que hubieren tomado conocimiento de información clasificada, estarán obligados a mantener tal carácter y su contenido, aún después del término de sus funciones en las respectivas organizaciones, pero no establece plazo alguno. ${ }^{14}$ Eventualmente, sería por el plazo de 25 años, término fijado como plazo máximo de clasificación en el artículo 33, contados a partir de su elaboración y clasificación. Pero dicho plazo podría aún ser modificado, por resolución del Poder Ejecutivo.

Lo expresado no parece razonable. Debe recordarse que la ley 19.121, Estatuto del Funcionario de la Administración Central, en el artículo 29, numeral 7, impone al servidor público (como lo son los funcionarios de los servicios de inteligencia) el deber de utilizar la información o conocimientos derivados de su calidad funcional a los efectos de su

13 Decreto 232/010, artículo 25. Prueba de daño. - La información podrá clasificarse como reservada, siempre que en la resolución de la autoridad responsable, debidamente fundada y motivada, se demuestre la existencia de elementos objetivos que permitan determinar la expectativa razonable de un daño al interés público protegido, de acuerdo con lo establecido en el artículo $9^{\circ}$ de la Ley que se reglamenta.

14 Cabe precisar que, conforme el inciso $2^{\circ}$ del artículo 31, dicha obligación de mantener la clasificación de la existencia o contenido de información a la que accedan por razones estrictamente justificadas, rige además para aquellas personas físicas o jurídicas que, sin ser integrantes del Sistema Nacional de Inteligencia de Estado, en razón de sus funciones o actividad que desempeñen, estén vinculadas circunstancialmente o aún excepcionalmente a dicha actividad. 
tarea, con la reserva debida. Se trata de un típico deber inherente al desempeño del cargo (Javier, J., 2018, pp. 90 - 92).

El ordinal refiere a "mantener reserva sobre asuntos e informaciones conocidos en razón de su función, aún después de haber cesado en la relación funcional". Ello supone una actitud prudente por parte del funcionario, que no debe comentar públicamente actos o hechos que llegaron a su conocimiento en razón del cargo que ocupa.

Ello no contradice el principio de transparencia, pues esta es la regla y la excepción, el secreto. Precisamente, la transparencia permite que la sociedad tenga el derecho a estar informada sobre la actividad de la Administración y que se presuma pública la información en poder de esta, conforme lo establecido en la ley 18.381 y en el artículo 18 del decreto $30 / 003$.

4.7. Tal conducta queda atrapada en el delito establecido en el artículo 163 Bis del Código Penal, incorporado por la ley 17.060, que tipifica el delito de Utilización indebida de información privilegiada.

La violación del deber de reserva ${ }^{15}$ supone incurrir en el delito de Revelación de Secretos, tipificado en el artículo 163 del Código Penal, en redacción dada por la ley 17.060, que torna punible la revelación del secreto administrativo, siempre y cuando la revelación no constituya un delito mayor (artículo 132 numeral $3^{\circ}$ del Código Penal) o comprometa intereses o secretos de los particulares (artículo 296 y siguientes del Código citado).

También sería aplicable el artículo 163 BIS del Código Penal (Utilización indebida de información privilegiada) ${ }_{1}^{16}$ en caso de que la conducta del funcionario sea contraria a la probidad, conforme lo establecido en el artículo 12, literal E), del decreto 30/003.

La referencia a que el secreto persiste "aún después de haber cesado la relación funcional", se corresponde con la referencia contenida en el artículo 163 del Código Penal, en cuanto prevé la posibilidad de que un ex funcionario cometa el delito, revelando secretos obtenidos durante el desempeño del cargo (por él conocidos o poseídos en razón de su empleo actual o anterior...", plantea la pregunta de hasta cuándo se debe mantener dicha reserva.

Por tanto, no existe plazo para esta situación específica, pero por analogía in bonam partem podría aplicarse el plazo de dos años establecido en el artículo 76 inciso $2^{\circ}$ de la ley (segunda) Orgánica Policial 19.315, de 19 de diciembre de 2015, en redacción dada por

15 Decreto 30/003, artículo $18^{\circ}$.- (Transparencia y publicidad). El funcionario público debe actuar con transparencia en el cumplimiento de su función.

Los actos, documentos y demás elementos relativos a la función pública pueden ser divulgados libremente, salvo que por su naturaleza deban permanecer reservados o secretos o hayan sido declarados tales por ley o resolución fundada, en todo caso bajo la responsabilidad a que hubiere lugar por derecho (art. $7^{\circ}$ de la ley 17.060 y 21 del decreto 354/999).

Queda comprendido en lo dispuesto precedentemente el deber de garantizar a los particulares interesados que lo solicitaren el acceso a aquellas informaciones que resulten del empleo y aplicación de medios informáticos y telemáticos para el desarrollo de las actividades de las Administraciones públicas y el ejercicio de sus competencias (art. 694 de la ley 16.736 de 5 de enero de 1996). 16 Código Penal, artículo 163 BIS. (Utilización indebida de información privilegiada)

El funcionario público que, con el fin de obtener un provecho económico para sí o para un tercero, haga uso indebido de la información o de datos de carácter reservado que haya conocido en razón o en ocasión de su empleo, será castigado con tres meses de prisión a cuatro años de penitenciaría, inhabilitación especial de dos a cuatro años y multa de 10 UR (diez unidades reajustables) a $10.000 \mathrm{UR}$ (diez mil unidades reajustables).

Redacción dada por Ley $\mathrm{N}^{\circ} 17.060$, de 23 de diciembre de 1998, artículo $9^{\circ}$. 
la ley de Presupuesto Nacional 19.924, de 18 de diciembre de 2020, para que el personal policial sea pasible de responsabilidad administrativa luego de su pase a retiro.

Eventualmente, podría recurrirse al plazo de prescripción de los delitos, conforme los artículos 119 y 120 del Código Penal.

Todo sin perjuicio de lo que se dirá al analizarse el artículo 33.

4.8. El artículo 32 de la ley exime a los órganos de inteligencia de la obligación de presentar los informes dispuestos en el artículo $7^{\circ}$ de la referida ley $18.331,{ }^{17}$ que consagra una exclusión que, atento a las características, naturaleza y fines de los servicios de inteligencia, resulta compartible..

El artículo 33, inciso $1^{\circ}$, establece en veinticinco años el plazo máximo de clasificación de la información de cualquier tipo, en poder de los órganos y organismos de inteligencia, contados a partir de su elaboración y clasificación.

Conforme el inciso $2^{\circ}$, dicho período no podrá ser modificado mediante la reclasificación a categorías superiores, salvo que exista resolución expresa del Presidente de la República, actuando con el Consejo de Ministros, en mérito a la naturaleza de origen de la información y cuando permanezcan las causas que determinaron la clasificación original.

Por tanto, tal plazo, especialmente establecido para la información de inteligencia clasificada como "Reservada", puede ser modificado por resolución del Poder Ejecutivo, responsable máximo de la actividad de inteligencia en el país, actuando en Consejo de Ministros. ${ }^{18}$

En principio, cabría entender que ese plazo no podría extenderse, atento al término "máximo" empleado en el inciso $1^{\circ}$ del artículo, prohibiéndose la reclasificación a categorías superiores. Sin embargo, el artículo lo permite en cuanto permanezcan las causas que fundamentaron la clasificación asignada y en mérito a la naturaleza de origen (fuente cerrada, por ejemplo) de la información clasificada.

El artículo 11 de la ley 18.381, ${ }^{19}$ relativo al período de reserva de la información clasificada como tal, sólo admite la ampliación de dicho período cuando permanezcan y se justifiquen las causas que le dieron origen. Se requiere entonces, la continuidad o pervivencia de las causas que ameritaron la clasificación reservada y que las mismas actualmente se sigan justificando.

17 Artículo $7^{\circ}$. (Presentación de informes). - Todos los sujetos obligados por la presente ley presentarán ante el órgano de control, hasta el último día hábil del mes de marzo de cada año, un informe anual sobre el cumplimiento del derecho de acceso a la información pública, que contendrá:

A) Información del período anterior sobre el cumplimiento de las obligaciones que le asigna esta ley.

B) Detalle de las solicitudes de acceso a la información y el trámite dado a cada una de ellas.

Sin perjuicio de las disposiciones anteriores, estarán también obligados a producir un informe semestral actualizado conteniendo la lista de información reservada.

18 Debe recordarse que conforme la Constitución de la República, “Al Presidente de la República, actuando con el Ministro o Ministros respectivos, o con el Consejo de Ministros, corresponde:

$\left.1^{\circ}\right)$ La conservación del orden y tranquilidad en lo interior, y la seguridad en lo exterior.

$2^{\circ}$ ) El mando superior de todas las fuerzas armadas.".

19 Artículo 11. (Período de reserva).- La información clasificada previamente como reservada, permanecerá con tal carácter hasta un período de quince años desde su clasificación. La información reservada será desclasificada cuando se extingan las causas que dieron lugar a su clasificación. Sólo se ampliará el período de reserva sobre cierta documentación cuando permanezcan y se justifiquen las causas que le dieron origen. (subrayado y negrilla del autor). 
La ley de inteligencia de Estado requiere la naturaleza de origen, de donde ha provenido o recolectado la información protegida con tal clasificación.

Sin embargo, existe entre una y otra una importante diferencia, ya referida: el plazo de la reserva en el caso de la ley 18.381, de Derecho de Acceso a la Información Pública es de 15 años, que pueden ser prorrogados, en tanto en el caso de la ley 19.696, con las modificaciones de la LUC 19.899, el plazo establecido es de 25 años, conforme viene de expresarse.

El artículo 37 de la ley establece que cuando la información proceda de fuentes cerradas, ${ }^{20}$ conforme lo establecido en el numeral 2) literal $\mathrm{H}$ ) del artículo $3^{\circ}$ de la ley, la identidad $\mathrm{u}$ origen de la misma será siempre reservada, sin perjuicio de lo establecido en el artículo 34, esto es, de la excepción al carácter reservado de la información.

4.9. El artículo 34 de la ley establece como excepción al carácter reservado de la información, que la misma refiera a la violación de los derechos humanos o sea relevante para prevenir o investigar violaciones a los mismos, o incumpla con lo dispuesto en la Sección II de la Constitución de la República, violando los derechos, deberes y garantías que consagra, reconoce y recibe; sería el caso de violación de los papeles de los particulares, o de la correspondencia epistolar, telegráfica o de cualquier otra especie, expresamente prohibida por el artículo 28 de la Carta.

La excepción legal recoge, en parte, la inoponibilidad de la reserva en caso de información relativa a la violación de derechos humanos o que sea relevante para prevenirlos o investigarlos, ya establecida en el artículo 12 de la ley $18.381,{ }^{21}$ ampliándose ahora al referido incumplimiento de la Sección II de la Carta.

En este caso, no sería de aplicación el período de reserva, establecido en 15 años a contarse desde su clasificación, por el artículo 11 de la ley $18.381,{ }^{22}$ sino el de 25 años, establecido expresamente para la información reservada relativa a los servicios de inteligencia, en el artículo 33 inciso $1^{\circ}$.

Se trata, en definitiva, de información que podría estar catalogada como reservada pero que, atento a la naturaleza de la misma (relativa a violaciones de derechos humanos o que tenga relevancia para prevenirlos o investigarlos), se accede a su entrega, pese a la clasificación asignada.

4.10. Conforme el artículo 35 de la ley, en el inciso $1^{\circ}$, en casos de revelación de información clasificada, en violación de las normas legales referidas a la clasificación y

20 Conforme la definición del artículo $3^{\circ}$, literal H) numeral 2 de la ley, fuentes cerradas son aquellas cuyo acceso es restringido y que para la obtención de la información es necesario el uso de medios y procedimientos especiales.

Se trata de datos o información protegidos, no públicos, sino confidenciales o secretos, cuya obtención resulta más compleja y requiere, por lo general, de procedimientos especiales, como el empleo del agente encubierto y ello justifica la negativa de su libre acceso y disposición, así como lo dispuesto en el artículo 37.

21 Ley 18.381, artículo 12. (Inoponibilidad en casos de violaciones a los derechos humanos).- Los sujetos obligados por esta ley no podrán invocar ninguna de las reservas mencionadas en los artículos que anteceden cuando la información solicitada se refiera a violaciones de derechos humanos o sea relevante para investigar, prevenir o evitar violaciones de los mismos.

22 Artículo 11. (Período de reserva).- La información clasificada previamente como reservada, permanecerá con tal carácter hasta un período de quince años desde su clasificación. La información reservada será desclasificada cuando se extingan las causas que dieron lugar a su clasificación. Sólo se ampliará el período de reserva sobre cierta documentación cuando permanezcan y se justifiquen las causas que le dieron origen. (cursiva del autor). 
a la revelación inapropiada de información, será de aplicación lo dispuesto en el artículo 132 numeral 3 del Título I del Libro II del Código Penal. ${ }^{23}$

Atento a su inciso $2^{\circ}$, si dicha violación fuera cometida por un funcionario público, será considerada falta gravísima y causal de destitución, previo procedimiento disciplinario, sin perjuicio de lo dispuesto en el inciso anterior o de las previsiones contenidas en los ordenamientos legales específicos de los órganos integrantes del Sistema Nacional de Inteligencia de Estado.

En relación con el referido artículo, señalaba el Profesor LANGÓN que en esta modalidad de espionaje se trata de preservar el secreto político o militar, concerniente a la seguridad del Estado, ya sea en su modalidad de "revelación" directa, ya en el mero hecho de "facilitar" el conocimiento de dicha información (Langón Cuñarro, 2017, p. 295).

"Revelar" significa descorrer el velo, descubrir, hacer conocer lo desconocido o secreto, tanto singularmente a una persona determinada, como a varias, por cualquier medio.

"Facilitar" es favorecer, ayudar, contribuir, volver fácil, sin dificultades, sencillo, sin mayor esfuerzo, hacer alguna cosa, en el caso, obtener el conocimiento del secreto de Estado que se pretende preservar.

Estos secretos, ya sean referidos a la actividad gubernamental (secretos políticos), como a la militar, deben concretarse en la protección de la seguridad del Estado, debiendo determinarse el carácter secreto o reservado del asunto, ya sea considerando su naturaleza objetiva, o la voluntad de reserva del titular de la información, o la limitación normativa de acceso a la misma.

Conforme LANGÓN, el bien jurídico protegido en estos delitos "de traición" es la soberanía nacional, bien jurídico colectivo y difuso, supraindividual, cuyo titular son todos los habitantes, representados por el Estado, que viene a ser el sujeto pasivo de estos delitos (Langón Cuñarro, 2017, pp. 293 y 295).

4.11. El artículo 36 de la ley refiere al acceso a la información del Sistema Nacional de Inteligencia de Estado. Su denominación fue modificada por la LUC 19.889, en el artículo 126, que le agregó la nota de "reservada" al nomen iuris del artículo: "Acceso a la información reservada del Sistema Nacional de Inteligencia de Estado".

El inciso $1^{\circ}$, reafirmando que la información producida y sistematizada por los organismos que conforman el Sistema Nacional de Inteligencia de Estado posee carácter absolutamente reservado, como se establece en el artículo 20 inciso $2^{\circ}$ y en los artículos 29,34 y 37, dispone que sólo podrá accederse a la misma por orden judicial y si es solicitada por la defensa de un indagado, imputado o acusado, términos sustituidos, conforme el nuevo Código del Proceso Penal por imputado, formalizado o condenado, lo cual puede crear discrepancias interpretativas.

Este inciso $1^{\circ}$ del artículo 36 tiene un agregado, realizado por el referido artículo 126 de la LUC, que exceptúa de este régimen a la información secreta, la que se regirá conforme lo establecido en el inciso tercero del artículo 29, ya comentado.

23 Código Penal. Artículo 132. Será castigado con diez a treinta años de penitenciaría, y de dos a diez años de inhabilitación absoluta: 3. (Revelación de secretos). El ciudadano que revelare secretos políticos o militares, concernientes a la seguridad del Estado, o facilitare su conocimiento. 
El inciso $2^{\circ}$, señala que la información producida y sistematizada por los organismos que conforman el Sistema Nacional de Inteligencia de Estado carece por sí sola de valor probatorio inculpatorio, conforme el artículo 22 de la Constitución de la República, en referencia a la prohibición constitucional de llevar adelante pesquisas secretas, sin autorización judicial, lo cual enfatiza que su actuación se encuentra sometida al control jurisdiccional, sin perjuicio de los contralores parlamentarios.

Cabe reafirmar que los servicios de inteligencia deben estar sujetos a las leyes relativas a la protección de datos personales y secreto de las comunicaciones, sin perjuicio de que se les confieran "poderes o procedimientos especiales", como los del artículo 20 inciso $5^{\circ}$ de la ley 19.696, o aún "poderes ampliados" (Pérez Villalobos, 2008, pp. 409 - 430). ${ }^{24}$

\section{De los Cometidos de la Secretaría de Inteligencia Estratégica}

Conforme la redacción dada al artículo $11^{25}$ por el artículo 120 de la LUC 19.889, los Cometidos y acceso a la información por parte de la SIEE (esta última referencia agregada por la LUC) revisten suma importancia, estableciéndose expresamente cuales son las actividades que puede (y debe) cumplir la SIEE, como órgano de coordinación del Sistema de Inteligencia Nacional.

Conforme el inciso 2 del artículo, el Informe Anual de Actividades de Inteligencia del Director de la SIEE deberá incluir aspectos presupuestales, de gestión, el Plan Nacional

24 Estos "poderes ampliados" de los servicios de inteligencia, susceptibles de afectar directamente los derechos fundamentales, implican la posibilidad de realizar tareas como vigilancia, registro y rastreo de información; registro de espacios o examen de objetos cerrados; abrir documentos sin consentimiento del remitente o destinatario; utilizar identidades falsas o robadas; claves, programas especiales de software o señales para acceder o copiar bases de datos de forma secreta; intervenir, recibir, grabar y supervisar conversaciones, telecomunicaciones u otros movimientos o transferencias de datos; acudir a proveedores de redes y servicios públicos de telecomunicaciones para requerir información sobre la identidad de los usuarios o sobre el tráfico pasado o futuro; tener acceso a cualquier lugar para instalar puestos de observación, etc.

25 Artículo 11. (Cometidos y acceso a la información por parte de la Secretaría de Inteligencia Estratégica de Estado).- La Secretaría de Inteligencia Estratégica de Estado deberá dar cumplimiento a los siguientes cometidos:

A) Formular el Plan Nacional de Inteligencia, para conocimiento y aprobación del Poder Ejecutivo.

B) Diseñar y ejecutar los programas y presupuestos de Inteligencia inscriptos en el Plan Nacional de Inteligencia.

C) Dirigir técnicamente el funcionamiento del Sistema Nacional de Inteligencia de Estado.

D) Procesar la información proporcionada por los órganos integrantes del Sistema Nacional de Inteligencia de Estado, en los ámbitos

nacional e internacional, con el fin de producir inteligencia estratégica de Estado.

E) Conducir el relacionamiento con los organismos de inteligencia estratégica de otros Estados.

F) Formular normas y procedimientos estandarizados comunes para todos los órganos del Sistema Nacional de Inteligencia de Estado.

G) Disponer la aplicación de medidas de inteligencia y contrainteligencia, con el objeto de detectar y enfrentar las amenazas definidas por la política de Defensa Nacional, así como otras amenazas al Estado.

H) Presentar los informes a que refiere esta ley, particularmente el Informe Anual de Actividades de Inteligencia, así como informes periódicos regulares de acuerdo a lo dispuesto en el Capítulo II del Título IV de la presente ley.

El Informe Anual de Actividades de Inteligencia deberá incluir aspectos presupuestales, de gestión, el Plan Nacional de Inteligencia, el plan de recolección de datos y directivas de trabajo de cada una de las agencias que desarrollan actividades de inteligencia de Estado. Este informe del Director de la Secretaría de Inteligencia Estratégica de Estado deberá permitir el control efectivo del cumplimiento del Sistema Nacional de Inteligencia, así como la legalidad y efectividad de las tareas y actividades realizadas.

El cumplimiento de dicha obligación deberá ser compatible con la no divulgación de información que pueda comprometer personas o fuentes y la necesidad del ejercicio del control parlamentario.

Para el cumplimiento de sus cometidos la Secretaría de Inteligencia Estratégica de Estado podrá requerir la información que estime necesaria de los órganos estatales, así como de las personas públicas no estatales

o personas jurídicas de derecho privado cuyo capital social esté constituido, en parte o en su totalidad, por participaciones, cuotas sociales de acciones nominativas propiedad del Estado o de personas públicas no estatales.

Los mencionados órganos estarán obligados a suministrar los antecedentes e informes en los mismos términos en que les sean solicitados, a través de la respectiva jefatura superior u órgano de dirección, según corresponda, no siendo oponibles las disposiciones vinculadas al secreto o la reserva. (negrillas en el texto, del autor). 
de Inteligencia, el plan de colección de datos y directivas de trabajo de cada una de las agencias que desarrollan actividades de inteligencia de Estado y deberá permitir el control efectivo del cumplimiento del Sistema Nacional de Inteligencia, así como de la legalidad y efectividad de las tareas y actividades realizadas cuidando, atento al inciso $3^{\circ}$, de no divulgar información que pueda comprometer personas o fuentes y la necesidad del ejercicio del control parlamentario.

La referencia a "Este informe del Director que viene de..." en la redacción original de la ley 19.696 correspondía al inciso $3^{\circ}$, pasando a integrar ahora el inciso $2^{\circ}$, en la redacción dada a este artículo por el 120 de la ley 19.889.

El inciso $4^{\circ}$ establece que para el cumplimiento de sus cometidos la Secretaría podrá requerir la información que estime necesaria de los órganos estatales, así como de las personas públicas no estatales o personas jurídicas de derecho privado cuyo capital social esté constituido, en su totalidad o en parte, por participaciones, cuotas sociales de acciones nominativas propiedad del Estado o de personas públicas no estatales, que conforme el inciso $5^{\circ}$, estarán obligados a suministrar los antecedentes e informes en los mismos términos en que les sean solicitados, a través de la respectiva jefatura superior u órgano de dirección, según corresponda y no les serán oponibles las disposiciones vinculadas al secreto o la reserva, agregado este último, realizado por el artículo 120 de la ley 19.889. .

Conforme lo expresado, todo género o tipo de información podrá ser solicitada por la SIEE a cualquier órgano estatal, centralizado, descentralizado territorialmente o por servicios, personas públicas no estatales y demás instituciones referidas, los cuales estarán en la obligación de aportarle la información "en los mismos términos en que les sean solicitados", esto es, dentro del plazo, condiciones, en la forma en que se solicite y directamente por el órgano de dirección o jefatura superior (no un subordinado) sin que pueda invocarse ninguna norma prohibitiva, en orden a la reserva o secreto de la información. Así, ni la DGI, o el BPS, o las Cajas paraestatales, podrán invocar el secreto tributario, o los Bancos estatales el secreto bancario, o aún un funcionario público ampararse en el secreto del cargo, o acudirse al secreto estadístico, para negar la información o antecedentes solicitados, sin perjuicio del deber que asume la Secretaría de no revelar o divulgar la información que reciba a su expreso pedido, que sólo podrá utilizar de acuerdo con los objetivos planteados y conforme el marco constitucional y legal vigente.

Como aspecto destacable, el literal C) del artículo 11, en redacción dada por el artículo 120 de la LUC 19.889, le asigna a la SIEE no sólo la tarea de coordinar el funcionamiento del Sistema, conforme el artículo $8^{\circ}$ de la ley 19.696, incisos $2^{\circ}$ y $3^{\circ}$ sino, además, la de "Dirigir técnicamente" su funcionamiento. Por tanto, no sólo coordina a los órganos de inteligencia, buscando coherencia, cooperación e intercambio de información entre ellos, sino que ahora su función primordial será dirigir, orientando, ordenando las actividades de inteligencia y mediante la planificación, organización, ejecución y control, alcanzar los fines y objetivos establecidos en el Plan Nacional de Inteligencia, impartiendo hacia tal fin las Directivas que sean pertinentes.

El literal D), de suma importancia práctica, le asigna la tarea fundamental de producir Inteligencia Estratégica de Estado, definida en el artículo $3^{\circ}$ literal C) y ya referida, a cuyo fin procesará la información proporcionada por los órganos que integran el SNIE, en el ámbito nacional e internacional. 
El literal F), en la redacción dada por el artículo 120 de la ley 19.889, le confiere ahora a la SIEE la facultad de "Formular" (no ya de "Proponer", conforme el texto anterior) normas y procedimientos estandarizados comunes para todos los órganos del Sistema, lo cual resulta clave para el ejercicio del cometido fundamental de dirección técnica y de la coordinación del SNIE.

El literal G) le confiere una potestad que implica cierta autonomía, pues le autoriza a disponer la aplicación de medidas de Inteligencia y de Contrainteligencia, definidas en el artículo $3^{\circ}$, literales A) y B), con el objeto de detectar y enfrentar las amenazas definidas por la Política de Defensa Nacional, así como otras amenazas al Estado. Estimo que tales medidas deberán adoptarse bajo la dirección del Poder Ejecutivo, como responsable último de la política de Inteligencia del país, sin perjuicio de la desconcentración que le otorga la ley en el artículo 10. Esta conclusión se fundamenta en el artículo 168 numeral $1^{\mathrm{o}}$ de la Constitución, ${ }^{26}$ pues si se trata de una situación que implique peligro para el país (ataque terrorista, invasión militar, ataque cibernético, etc.) es el Poder Ejecutivo, en acuerdo plural o singular o en Consejo de Ministros, el órgano que debe resolver, como máximo responsable de la seguridad interior y exterior de la República.

\section{Conclusiones finales}

La ley de Inteligencia de Estado, ha sido producto en Uruguay de un acuerdo político y con un objeto, principios generales, objetivos y cometidos expresamente establecidos, reconociéndose la necesidad del país de contar con una norma que le otorgara herramientas para afrontar los nuevos desafíos que se presentan actualmente, en diversos niveles, además de planificar las estrategias que se necesitan desarrollar.

La experiencia marcará el camino. Pero los servicios de inteligencia deberán cumplir con sus cometidos conforme el fin debido: produciendo inteligencia estratégica para la toma de decisiones trascendentes al más alto nivel de gobierno. Para ello se le han otorgado facultades excepcionales, como las que implican los denominados "procedimientos especiales", o la actuación encubierta de sus agentes, o conforme la modificación introducida por la LUC, la posibilidad de declarar determinados registros, actos o documentos o sus actividades, entre otros, como secretos. Pero en contraposición de esa particular concesión que la sociedad realiza para que la proteja de la injerencia o daño doméstico o exterior, deben existir y admitirse férreos controles institucionales, así como la transparencia en su actuación y en el manejo de los fondos que le sean asignados.

Pero lo que debe reafirmarse y tenerse siempre presente, es que no existe riesgo o peligro alguno que justifique el apartamiento de los órganos de Inteligencia de su deber primordial: desarrollar su actuación bajo las normas impuestas por el régimen de Estado de Derecho, pues nada puede justificar la lesión o desconocimiento de los derechos de las personas. Pues de eso se trata, de protegerlos y no de conculcarlos, favoreciendo su efectividad y pleno goce. 


\section{Referencias bibliográficas}

Bandeira de Mello, C. A. (2006) Curso de Derecho Administrativo, Primera edición en español. México: Editorial Porrúa México - UNAM.

Bayardo Bengoa, F. (1961). La Tutela Penal del Secreto, Montevideo: Facultad de Derecho y Ciencias Sociales, pp. 16 - 27.

Berridge, G. R, \& James, A. (2001). A Dictionary of Diplomacy. UK: Palgrave Macmillan.

Bull, H. (1995) The Anarchical Society. A Study of Order in World Politics, $2^{\text {a }}$ edición, New York: Columbia UP, p. 172. Recuperado en https://link.springer.com/book/10.1007\% 2F978-1-349-24028-9.

Cajarville, J. P. (2012). Delegación de Atribuciones (Distribución de competencias en la organización estatal: centralización y descentralización, concentración y desconcentración. Distribución de tareas. Delegación). Sobre Derecho Administrativo p. 603). Tercera Edición Actualizada y Ampliada. Montevideo, Fcu, Tomo I.

Correa Freitas, R. (2014). Derecho Constitucional Contemporáneo, Cuarta Edición Actualizada. T. II. Montevideo: FCU.

Correa Freitas, R. y Vásquez, C. (2011). Manual de Derecho de la Función Pública, Segunda Edición. Montevideo: FCU.

Delpiazzo, C. (2017). Ética y administración pública. Montevideo: La Ley Uruguay.

Delpiazzo, C. (2014). Normas de contenido ético en el Estatuto del Funcionario. Duran Martínez, A. (Coordinador) Funcionarios Públicos. Especial énfasis en la ley 19.121. Montevideo: Grupo Magro Editores.

Delpiazzo, C. (2011). Derecho Administrativo General. Volumen I, $1^{\text {a }}$ Edición. Montevideo: Editorial y Librería Jurídica Amalio Fernández.

Del Pozo, F. (2019). La responsabilidad de compartir y la necesidad de saber. Boletín IEEE, ISSN-e 2530-125X, No 14, p. 436. Recuperado en http:/ /www.ieee.es/Galerias/fichero/docs_opinion/2019/DIEEEO33_2019FERPOZ-compartir.pdf.

Duran Martínez, A. (2012) Derecho a la protección de datos personales y al acceso a la Información Pública. Hábeas Data. Leyes $N^{o} 18.331$ de 11 de agosto de 2008 y No 18.381 de 17 de octubre de 2008. $2^{\mathrm{a}}$ Edición actualizada y ampliada. Montevideo: Editorial y Librería Jurídica Amalio M. Fernández.

Durán Martínez, A. \& Hanna de Rosa, M. (2013). Ética. Estado de Derecho. Buena Administración. Montevideo: Mastergraf.

Heidenrich, J. (2007), The State of Strategic Intelligence. Studies in Intelligence, 51(2). Recuperado de https://www.cia.gov/library/center-for-the-study-of-intelligence/csi-publications/csi-studies/studies/vol51no2/the-state-of-strategic-intelligence.html.

Holzmann, G. y Gallardo, M. (1997). La función del sistema nacional de inteligencia en un estado democrático. Revista de Ciencia Política, 35, p. 118. Recuperado en https: / / revistapolitica.uchile.cl/index.php/RP/article/view/55040/58044 
Jackson, P. y Siegel, J. (2005), Introduction, Intelligence and Statecraft: The Use and Limits of Intelligence in International Society (p.3), Westport, CT: Greenwood Publishing Group.

Javier, J. (2020). Inteligencia Nacional. La Secretaría de Inteligencia Estratégica y las modificaciones de la ley 19.889, XII Semana Académica del Instituto de Derecho Administrativo "Novedades de Derecho Administrativo en la LUC".

Javier, J. (2018). Ley 19.121. Estatuto del Funcionario Público de la Administración central. Análisis exegético. Montevideo: Universidad de Montevideo Facultad de Derecho, pp. 90-92.

Javier, J. (2016), Los cometidos esenciales del Estado de Seguridad Pública y de Defensa Nacional. Cuadernos de Derecho de la facultad de Ciencias Jurídicas de la Universidad de la Empresa, N 6. UDE: Montevideo, pp. 77-78. Recuperado en ude.edu.uy/cuadernode-derecho-6-los-cometidos-esenciales-del-estado/.

Javier, J. (2015). La Política de Defensa Nacional en Uruguay. Revista de Derecho Público, $N^{o} 47$, p. 73. Recuperado en http:/ / www.revistaderechopublico.com.uy/revistas/47/archivos/Juvenal47.pdf.

Javier, J. (2008) Ley de Procedimiento Policial. Análisis exegético de la Ley 18.315 de 5 de julio de 2008. Montevideo: Editorial y Librería Jurídica Amalio Fernández.

Keithly, D. (2010). Intelligence Fundamentals. En Keith G. Logan (Ed.), Homeland Security and Intelligence (pp. 43-58). Santa Barbara, California: Praeger Security International.

Korzeniak, J. (1998). Las Comisiones Parlamentarias de Investigación y sus facultades. Montevideo: FCU.

Langón Cuñarro, M. (2017). Código Penal Uruguayo y leyes penales complementarias comentados, Montevideo: UM.

Murillo Zamora, C. (2015). Diplomacia, inteligencia exterior y secreto diplomático frente a los desafíos de la era global. Revista Policía y seguridad pública, Vol. 2, (Nº5), p. 4546. Recuperado en https://www.lamjol.info/index.php/RPSP/article/view/2325.

Pérez Villalobos, M. C. (2008). El control de los servicios de inteligencia en los Estados democráticos. Actas del I Congreso Nacional de Inteligencia: La inteligencia como disciplina científica (pp.409-430). Madrid: Ministerio de Defensa; Plaza y Valdés. Recuperado en https://digibug.ugr.es/bitstream/handle/10481/27872/El\%20 control $\% 20$ democr $\%$ c3 $\%$ a1tico $\% 20$ de $\% 201$ os $\% 20$ servicios $\% 20$ de $\% 20$ inteligencia. pdf? sequence $=1 \&$ is Allowed $=\mathrm{y}$.

Ponte, G. (2016). Inteligencia: Desde sus Nociones Básicas hasta su Actual Estatus Estratégico. Revista de la Escuela Superior de Guerra, No 592, pp. 95-96. Recuperado en http:/ / www.cefadigital.edu.ar/bitstream/1847939/963/1/Revista\%20ESG\%20 no.592-2016_Ponte_150.pdf

Prat, J. (1978) Derecho Administrativo, Tomo 3, Volumen 1, Montevideo: Acali Editorial.

Ruiz Miguel, C. (2002). Servicios de inteligencia y seguridad del Estado constitucional, Madrid: Tecnos. 
Sansó, D. y Pascual, R. (2019), Los servicios de inteligencia como objeto extraño de regulación constitucional. RESI: Revista de estudios en seguridad internacional, Vol. 5, (No2), pp. 127-138. Recuperado de http://www.seguridadinternacional.es/ revista / ?q=content/los-servicios-de-inteligencia-como-objeto-extra\%C3\%B1o-deregulaci $\% \mathrm{C} 3 \% \mathrm{~B} 3 \mathrm{n}$-constitucional.

Ugarte, J. M. (2003). El control de la actividad de inteligencia: Realidad actual y tendencias hacia el futuro: Un análisis centrado en América Latina. Estudios de Seguridad y Defensa (REDES). CHDS, Santiago de Chile. Recuperado en https: / / www.resdal. org/producciones-miembros/redes-03-ugarte.pdf. 